\title{
Identification of Colletotrichum Species Responsible for Anthracnose and Root Necrosis of Strawberry in Israel
}

\author{
S. Freeman and T. Katan
}

Department of Plant Pathology, ARO, The Volcani Center, P.O. Box 6, Bet Dagan 50250, Israel. Accepted for publication 4 February 1997.

\begin{abstract}
Freeman, S., and Katan, T. 1997. Identification of Colletotrichum species responsible for anthracnose and root necrosis of strawberry in Israel. Phytopathology 87:516-521.

Strawberry anthracnose was observed for the first time in Israel in 1995. The disease reached epidemic proportions in Israeli nurseries and production fields in 1995 and 1996. Using morphological and cultural characteristics, the species responsible for anthracnose was identified as Colletotrichum acutatum. A reliable semi-selective medium, amended with iprodione and lactic acid, was used to isolate the fungus from infected tissues. In addition, $C$. acutatum was subsequently isolated from necrotic roots of stunted, chlorotic plants that exhibited no symptoms of anthracnose. High levels of the pathogen from naturally infested field soil and perlite growth substrate were quantified from the rhizosphere of diseased plants on the iprodione-amended medium. Both foliar- and root-
\end{abstract}

ABSTRACT infecting isolates were equally pathogenic to strawberry, causing 95 to $100 \%$ plant mortality, when inoculated on roots and foliage. In complementation (heterokaryon) tests using nitrate nonutilizing mutants, 113 out of 115 isolates from different plant parts and locations belonged to a single vegetative compatibility group. Arbitrarily primed polymerase chain reaction of genomic DNA using four repetitive-motif primers produced nearly uniform amplified DNA banding patterns for 141 of the Israeli strawberry isolates from different sites, plots, plant tissues, and cultivars. When compared to reference isolates from the US, these band patterns suggested that a single introduction of $C$. acutatum was responsible for strawberry anthracnose on foliage and necrosis of roots in Israel.

Additional keywords: Colletotrichum fragariae, C. gloeosporioides, Fragaria $\times$ ananassa.
Several species of the fungal plant pathogen Colletotrichum cause strawberry (Fragaria $\times$ ananassa Duch.) anthracnose, a major disease of this crop. Principal pathogens known to be responsible for the disease are C. acutatum J.H. Simmonds, C. fragariae Brooks and C. gloeosporioides (Penz.) Penz. \& Sacc. in Penz. (teleomorph Glomerella cingulata (Stoneman) Spauld. \& H. Schrenk) $(19,28,29)$. Infections of mother plants with $C$. acutatum, which develop bud and eventually crown rot, result in the collapse and death of the plant. In the nursery, lesions are formed on stolons that eventually girdle the runners, resulting in the wilting and death of unrooted daughter plants distal to the lesion. The related pathogens $C$. gloeosporioides and $C$. fragariae cause symptoms similar to those caused by $C$. acutatum. Infected transplants are capable of spreading the disease from the nursery to the field, where typical anthracnose symptoms are later manifested as irregular and black leaf spot, crown rot, flower blight, and fruit rot (19). Considerable yield loss can be inflicted by anthracnose under the appropriate environmental and cultural conditions (18).

From May to September 1995 a severe outbreak of strawberry anthracnose was observed in several strawberry-growing nurseries in Israel $(10,11)$. Following transplantation to production fields during September and October, entire beds of strawberry plants collapsed. Typical anthracnose symptoms observed from November 1995 to June 1996 were crown rot, flower blight, and green and ripe fruit rot. This was the first record of strawberry anthracnose in Israel $(10,11)$. Moreover, in at least four production fields in the same region, hundreds of plants developed symptoms of stunting and chlorosis, phenomena that are atypical of strawberry anthracnose. When these plants were uprooted, most of their roots were dark brown and decayed. Colletotrichum was readily

Corresponding author: S. Freeman; E-mail address: vpsfreem@ volcani.agri.gov.il

Publication no. P-1997-0311-01R

(C) 1997 The American Phytopathological Society isolated from necrotic root tissues, although no foliar anthracnose was observed.

Traditional methods for discriminating between species of $\mathrm{Col}$ letotrichum have relied primarily on morphology, such as size and shape of the conidia, colony color, presence or absence of setae, and the existence of the teleomorph, G. cingulata $(16,29,31,32$, 34). However, due to environmental influences on the stability of morphological traits and the existence of intermediate forms, these criteria are not always adequate for the reliable differentiation of the Colletotrichum species responsible for strawberry anthracnose. Recently, various molecular techniques have been used to accurately identify the three main species causing strawberry anthracnose (13). Polymerase chain reaction (PCR), utilizing primers of repeat motifs, is a rapid and reliable molecular method for differentiating between the Colletotrichum complex (14). Studies of vegetative compatibility offer another approach to determining genetic relatedness in anamorphic populations of plant pathogens such as Fusarium oxysporum $(5,20,22,25)$ and Colletotrichum species $(4,6,21,35)$. Since the exchange of genetic material requires hyphal anastomosis, vegetatively compatible isolates are expected to be more similar to one another, thereby constituting a distinct genetic population $(9,23)$.

Strawberry anthracnose reached epidemic proportions in Israel during the 1995 to 1996 and current 1996 to 1997 growing seasons $(10,11)$. At the same time, plants exhibiting stunting, chlorosis, and root necrosis were observed in many production fields. The main purpose of this work was to characterize the species of Colletotrichum responsible for these symptoms and, more specifically, to determine whether anthracnose and root-necrosis diseases are incited by the same pathogen or different species. We characterized 147 isolates of Colletotrichum from typical diseased plants as well as atypical stunted, chlorotic plants with root necrosis. Vegetative compatibility tests with nitrate nonutilizing (nit) mutants were used to study the genetic composition of the pathogen population. PCR was used to compare the isolates among them- 
selves and to reference strains of the three Colletotrichum species from strawberry.

\section{MATERIALS AND METHODS}

Fungal cultures and growth conditions. The monoconidial Colletotrichum isolates used in this study are listed in Table 1. Reference Colletotrichum isolates C. acutatum (CA-310-1 and CA-330-1), C. fragariae (CF-63-1), and isolates of two discrete genotypes of $C$. gloeosporioides (CG-315-1 representing genotype Cgl-1, and CG-272-1 of genotype Cgl-2), were previously identified and characterized $(14,16)$. All Israeli cultures were isolated from symptomatic, infected strawberry plants (fruit, vegetative parts, and roots) from different cultivars, sites, and plots during the 1995 to 1996 season. Infected plant parts were surface-disinfested (3\% sodium hypochlorite) and plated on modified Mathur's medium (MS; $0.1 \%$ yeast extract, $0.1 \%$ bactopeptone, $1 \%$ sucrose, $0.25 \%$ $\mathrm{MgSO}_{4} \cdot 7 \mathrm{H}_{2} \mathrm{O}, 0.27 \% \mathrm{KH}_{2} \mathrm{PO}_{4}, 2 \%$ agar) (33) supplemented with $2.5 \mu \mathrm{g}$ (a.i.) of iprodione (Rovral 50WP) per $\mathrm{ml}$ and acidified with
$0.1 \%$ lactic acid to suppress growth of fungal contaminants and bacteria. Cultures were grown on $\mathrm{MS}$ at $25^{\circ} \mathrm{C}$ in the dark and characterized morphologically. Cultures were also transferred to potato dextrose agar (PDA) to verify identification.

Quantification of the pathogen in the rhizosphere and roots of diseased plants. During January 1996, 4 months after transplanting, field soil (from three commercial fields in the Sharon region) and perlite growth substrate (from a breeding plot at the Volcani Center) were collected from the rhizosphere of naturally infected plants showing symptoms of stunting and chlorosis. Soil and perlite samples (5 $\mathrm{g}$ each and replicated five times) were agitated in $45 \mathrm{ml}$ of sterile distilled water for $30 \mathrm{~min}$ and dilutionplated on supplemented MS to determine the number of CFU per gram of soil.

Eighty diseased plants (twenty each from the three fields and twenty from the perlite substrate) were assessed for presence of the pathogen in roots. Five necrotic root segments (each $1.5 \mathrm{~cm}$ long), chosen at random from each plant, were surface-disinfested and plated on the supplemented MS. Plates were incubated at

TABLE 1. Origin of Colletotrichum acutatum, C. fragariae, and C. gloeosporioides isolates from strawberry used in this study

\begin{tabular}{|c|c|c|c|c|c|c|c|c|}
\hline \multirow[b]{2}{*}{ Species } & \multirow[b]{2}{*}{ Isolate $^{\mathrm{a}}$} & \multirow[b]{2}{*}{ Origin } & \multirow[b]{2}{*}{ Site/plot } & \multirow[b]{2}{*}{ Cultivar } & \multirow[b]{2}{*}{ Organ } & \multicolumn{3}{|c|}{ Test $^{\mathrm{b}}$} \\
\hline & & & & & & Mol. & $\mathrm{VCG}$ & Path. \\
\hline C. fragariae & CF-63-1 & Miss., U.S. & $\ldots$ & $\ldots$ & Crown & + & & \\
\hline C. gloeosporioides & CG-272-1 & Fla., U.S. & $\ldots$ & $\ldots$ & Leaf & + & & \\
\hline C. gloeosporioides & CG-315-1 & Nova Scotia, Canada & $\ldots$ & $\ldots$ & Crown & + & & \\
\hline C. acutatum & CA-310-1 & N.C., U.S. & $\ldots$ & $\ldots$ & Leaf & + & & \\
\hline C. acutatum & CA-330-1 & Tenn., U.S. & $\ldots$ & $\ldots$ & Fruit & + & & \\
\hline C. acutatum & TUT-5954 & Israel & $\mathrm{PC}-\mathrm{BD}^{\mathrm{c}}$ & $\ldots$ & Crown & + & + & \\
\hline C. acutatum & TUT-232: $1^{\mathrm{d}}$ & Israel & $\mathrm{SPC}^{\mathrm{e}}$ & $\ldots$ & Crown & + & + & \\
\hline C. acutatum & TUT-718K ${ }^{\mathrm{f}}$ & Israel & Kadima/SPC & $\ldots$ & Crown & & + & \\
\hline C. acutatum & TUT-719P & Israel & Ein Vered/SPC & $\ldots$ & Crown & & + & \\
\hline C. acutatum & TUT-TIR1g & Israel & Tira & 543 & Crown & & + & \\
\hline C. acutatum & TUT-7E & Israel & Geulim & 543 & Crown & + & + & \\
\hline C. acutatum & TUT-22A ${ }^{\mathrm{i}}$ & Israel & Kadima/P & 329 & Crown & + & + & \\
\hline C. acutatum & TUT-24A ${ }^{\mathrm{j}}$ & Israel & Kadima/A & 216 & Crown & + & & \\
\hline C. acutatum & TUT-8V & Israel & Geulim & 543 & Stolon & + & + & \\
\hline C. acutatum & TUT-40A ${ }^{\mathrm{k}}$ & Israel & Kadima/P & Oso Grande & Stolon & + & + & \\
\hline C. acutatum & TUT-62A ${ }^{1}$ & Israel & Kadima/P & 543 & Stolon & + & + & \\
\hline C. acutatum & TUT-74A ${ }^{\mathrm{m}}$ & Israel & Kadima/V & 329 & Stolon & + & + & \\
\hline C. acutatum & TUT-80A ${ }^{\mathrm{n}}$ & Israel & Kadima/V & 156 & Stolon & + & + & \\
\hline C. acutatum & TUT-93A ${ }^{\circ}$ & Israel & Kadima/P & 329 & Stolon & + & + & \\
\hline C. acutatum & TUT-100A & Israel & Kadima/P & 543 & Fruit & + & & \\
\hline C. acutatum & TUT-106A ${ }^{q}$ & Israel & Kadima/H & 76 & Fruit & + & + & + \\
\hline C. acutatum & TUT-110A ${ }^{r}$ & Israel & Kadima/A & Oso Grande & Fruit & + & + & + \\
\hline C. acutatum & TUT-121A ${ }^{\mathrm{s}}$ & Israel & Kadima/A & 543 & Fruit & + & & \\
\hline C. acutatum & TUT-127A ${ }^{t}$ & Israel & Kadima/A & Oso Grande & Root & + & + & + \\
\hline C. acutatum & TUT-130A ${ }^{\mathrm{u}}$ & Israel & Geulim & 543 & Root & + & & \\
\hline C. acutatum & TUT-137A ${ }^{v}$ & Israel & Even-Y & Oso Grande & Root & + & + & + \\
\hline C. acutatum & TUT-140A ${ }^{w}$ & Israel & Kadima/B & 538 & Root & + & & \\
\hline
\end{tabular}

a Representative isolates originating from different sites, plots, cultivars, and infected tissues.

b Isolates that were tested (+) by molecular analyses (Mol.), vegetative compatibility grouping(VCG), and pathogenicity assays (Path.).

c Plant clinic, Bet Dagan.

d Additional isolate: TUT-232:2.

e Shelef plant clinic, Hod Hasharon, Israel.

f Additional isolates: TUT-742D and -743K.

g Additional isolate: TUT-TIR4.

h Additional isolates: TUT-6AB, -9A, -10A, -11A, -12A, -13A, -14A, and -15A.

i Additional isolates: TUT-16A, $-17 \mathrm{~A},-18 \mathrm{~A},-19 \mathrm{~A},-20 \mathrm{~A},-21 \mathrm{~A}$, and $-23 \mathrm{~A}$.

j Additional isolate: TUT-25A.

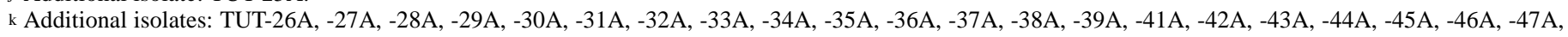

$-48 \mathrm{~A},-49 \mathrm{~A},-50 \mathrm{~A},-51 \mathrm{~A},-52 \mathrm{~A},-53 \mathrm{~A},-54 \mathrm{~A},-55 \mathrm{~A},-56 \mathrm{~A},-57 \mathrm{~A}$, and $-58 \mathrm{~A}$.

1 Additional isolates: TUT-59A, -60A, and -61A.

m Additional isolates: TUT-63A, -64A, -65A, -66A, -67A, -68A, -69A, -70A, -71A, -72A, -73A, -75A, -76A, and -77A.

n Additional isolates: TUT-78A, -79A, -81A, -82A, -83A, -84A, -85A, -86A, and -87A.

o Additional isolates: TUT-89A, -90A, -91A, -92A, -94A, -95A, -96A, -97A, -98A, and -99A.

p Additional isolates: TUT-101A, -102A, -103A, -104A, -105A, -122A, -123A, and -124A.

q Additional isolates: TUT-107A, -108A, and -109A.

$\mathrm{r}$ Additional isolates: TUT-111A and -112A.

s Additional isolates: TUT-113A, -114A, -115A, -116A, -117A, -118A, -119A, and -120A.

t Additional isolates: TUT-125A, -126A, -128A, and -129A.

u Additional isolates: TUT-131A, -132A, -133A, and -134A.

v Additional isolates: TUT-135A, $-136 \mathrm{~A},-138 \mathrm{~A}$, and -139A.

w Additional isolates: TUT-141A, -142A, -143A, and -144A. 
$25^{\circ} \mathrm{C}$ for 5 to 7 days and segments that yielded colonies of $\mathrm{Col}$ letotrichum were counted. Results were expressed as the percentage of infected roots of plants growing in soil and perlite.

Foliar and root pathogenicity assays. Six-week-old strawberry plants (certified disease-free, Rahan nursery, Israel) of two cultivars (Chandler and Sharon) were used for foliar- and rootinoculation experiments. Plant foliage was inoculated by spraying conidial suspensions $\left(10^{6} / \mathrm{ml}\right)$ of two fruit isolates (TUT-106A and TUT-110A), two root isolates (TUT-127A and TUT-137A), and a water control until runoff. Ten plants of each cultivar were inoculated with each isolate separately, and maintained in a greenhouse at $25^{\circ} \mathrm{C}$, under natural daylight conditions. Disease progress was assessed as the percentage of plant mortality after 7 to 10 and 30 days. The experiment was conducted twice.

Plant roots (Chandler and Sharon cultivars) were inoculated by dipping in conidial suspensions $\left(10^{6} / \mathrm{ml}\right)$ of two fruit isolates (TUT106A and TUT-110A) and two root isolates (TUT-127A and TUT137A) for $10 \mathrm{~min}, 4 \mathrm{~h}$, and $18 \mathrm{~h}$ periods. Plants were then transferred to pots $(15 \mathrm{~cm}$ diameter) in a peat/tuff (volcanic ash) $(1: 1$, $\mathrm{vol} / \mathrm{vol}$ ) medium. Ten plants of each cultivar were inoculated with each isolate separately with comparable water controls. Plants were maintained in the greenhouse under conditions identical to those described for the foliar inoculations. Percentage of plant mortality was determined 21 days after inoculation for each treatment. Percentage of infected roots was calculated as described. The experiment was conducted three times consecutively over a 3-week period, dictated by the availability of plants for inoculation. Results of the three experiments were pooled. Statistical analysis of

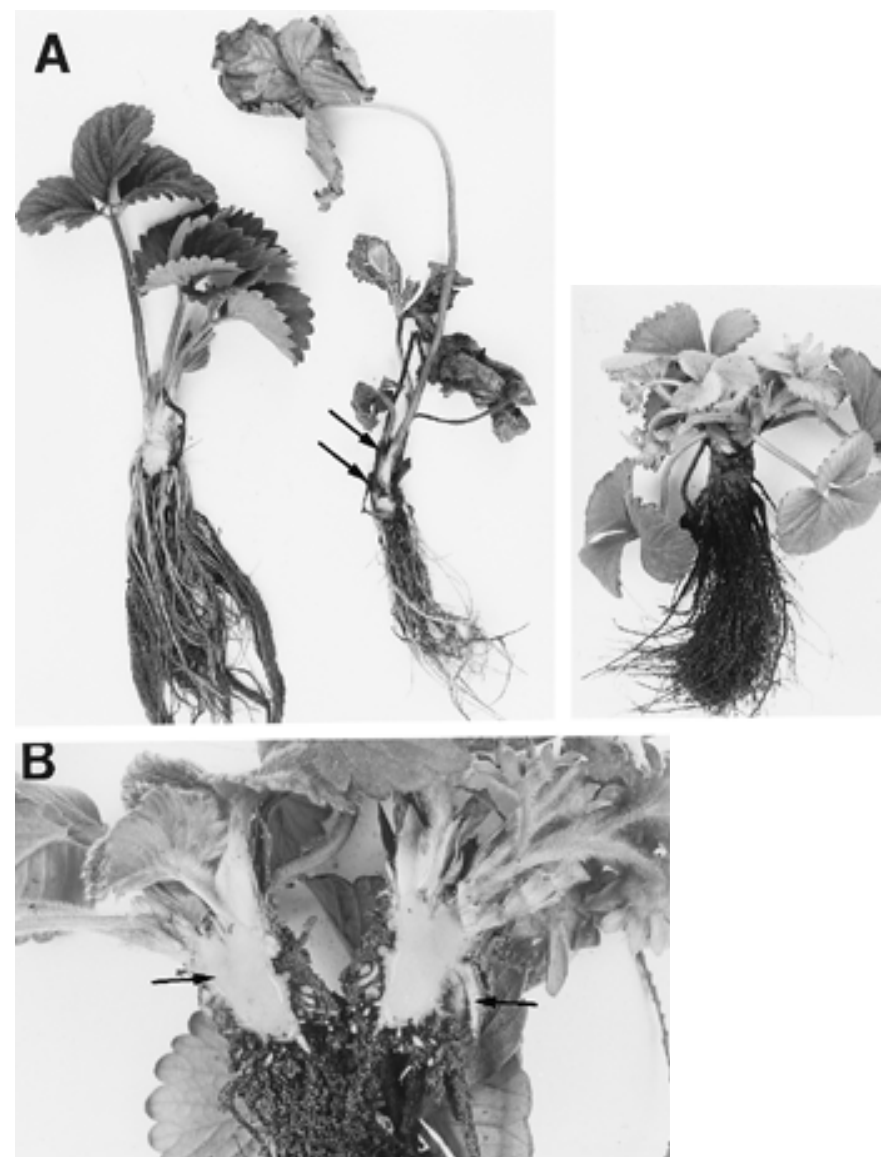

Fig. 1. A, Strawberry plant (cv. Oso Grande) with a healthy crown and root system (left). Anthracnose-infected plant (cv. Oso Grande), caused by Colletotrichum acutatum, showing symptoms of wilting, bud and crown rot denoted by arrows, with a healthy root system (middle). Stunted, chlorotic plant exhibiting atypical root necrosis with brown discoloration caused by $\mathrm{C}$. $\mathrm{acu}$ tatum (right). B, Crowns of plants with decayed root systems appear to remain healthy (longitudinal sections denoted by arrows). plant mortality following root inoculation with different isolates and dipping periods was performed by two-way analysis of variance, using the SAS statistical program (SAS Institute, Cary, NC).

Vegetative compatibility grouping. Puhalla's minimal nitrate agar (MM), a sucrose-salt medium containing nitrate as the nitrogen source (25), was used to recognize nit mutants and for complementation (heterokaryon) tests. Chlorate media, based on MM or PDA amended with $\mathrm{KClO}_{3}$ (15 or $25 \mathrm{~g} /$ liter, respectively), were used to generate nit mutants $(5,25)$. Plates $(9 \mathrm{~cm}$ diameter) of chlorate media were centrally inoculated with small mycelial plugs and incubated at 24 to $27^{\circ} \mathrm{C}$. Fast-growing sectors emerging from the restricted colonies were transferred to $\mathrm{MM}$ plates $(5 \mathrm{~cm}$ diameter) and examined after a 4-day incubation period. Colonies with a thin expanding mycelium were considered nit mutants. Partial phenotype characterization of nit mutants was attempted using nitrite, hypoxanthine, and ammonium media $(2,5,21)$. Complementation between nit mutants was tested on MM as described (21). Heterokaryons were usually evident within 10 to 15 days. When mutants of two different isolates formed a heterokaryon, their parent isolates were assigned to the same vegetative compatibility group (VCG).

Isolation and purification of fungal DNA. Liquid cultures comprising $100 \mathrm{ml}$ of $\mathrm{MS}$ in 250-ml Erlenmeyer flasks were inoculated with five mycelial disks derived from colony margins. The cultures were agitated for 5 to 6 days on a rotary shaker (150 $\mathrm{rpm}, 25^{\circ} \mathrm{C}$ ), and fragmented $12 \mathrm{~h}$ before harvesting the mycelia by blending for $10 \mathrm{~s}$ at $24,000 \mathrm{rpm}$ with a tissue homogenizer (UltraTurrax T25, Janke \& Kunkel, IKA Labortechnik, Staufen, Germany) to stimulate new growth. Mycelia were collected by vacuum filtration and lyophilized until dry. DNA was extracted and purified as previously described (13). The DNA was dissolved in $0.5 \mathrm{ml}$ of TE buffer (10 mM Tris-HCl, $1 \mathrm{mM}$ EDTA; $\mathrm{pH}$ 8.0) to an approximate concentration of 200 to $500 \mu \mathrm{g} / \mathrm{ml}$, and diluted to a concentration of 10 to $100 \mathrm{ng} / \mathrm{ml}$ for PCR.

PCR amplification. For arbitrarily primed PCR (ap-PCR), primers were derived from microsatellite or repeat sequences as follows: CAGCAGCAGCAGCAG (26), TGTCTGTCTGTCTGTC (13), GACACGACACGACAC (17), GACAGACAGACAGACA (36). In the text, these primers appear as $(\mathrm{CAG})_{5}$, (TGTC $)_{4}$, (GA$\mathrm{CAC})_{3}$ and $(\mathrm{GACA})_{4}$, respectively. PCR reactions were performed in a total volume of $20 \mu \mathrm{l}$, containing 10 to $100 \mathrm{ng}$ genomic DNA, $50 \mathrm{mM} \mathrm{KCl}, 10 \mathrm{mM}$ Tris- $\mathrm{HCl}, 0.2 \mathrm{mM}$ each of dATP, dCTP, dGTP, and dTTP, $1.5 \mathrm{mM} \mathrm{MgCl}, 1$ unit of Taq DNA polymerase (Promega, Madison, WI), and $1 \mu \mathrm{M}$ primer. The reactions were incubated in a Hybaid thermocycler (Hybaid Ltd., Teddington, England), beginning with $5 \mathrm{~min}$ of denaturation at $95^{\circ} \mathrm{C}$, followed by 30 cycles consisting of $30 \mathrm{~s}$ at $95^{\circ} \mathrm{C}, 30 \mathrm{~s}$ at either $60^{\circ} \mathrm{C}$ [for $(\mathrm{CAG})_{5}$ ] or $48^{\circ} \mathrm{C}$ [for $(\mathrm{GACA})_{4},(\mathrm{GACAC})_{3}$, and (TGTC $)_{4}$ ], and $1.5 \mathrm{~min}$ at $72^{\circ} \mathrm{C}$. Amplification products were separated in agarose gels $(1.5 \%$, $15 \times 10 \mathrm{~cm})$ in Tris-acetate-EDTA buffer (27) by electrophoresis at $80 \mathrm{~V}$ for $2 \mathrm{~h}$. Ap-PCR experiments were conducted at least three times for 141 isolates and two additional times for representative and reference isolates, with identical results being reproduced.

\section{RESULTS}

Characterization of Colletotrichum isolates originating from typical anthracnose-diseased and atypical, stunted plants. One hundred, forty-seven monoconidial isolates (one per plant) were characterized (Table 1). Of these, 127 were obtained from crown, stolon and fruit tissues of anthracnose-affected plants of six cultivars collected in seven commercial plots at four sites. The remaining 20 isolates were obtained from decaying roots of stunted chlorotic plants of three cultivars, collected in four plots at three sites.

Approximately 100 diseased plants showing symptoms of stunting and chlorosis were unearthed for visual examination of crowns and roots. These plants did not exhibit foliar symptoms of anthracnose. All crowns were apparently healthy, whereas most of the roots were necrotic with brown discoloration (Fig. 1). Colleto- 
trichum was readily recovered from roots plated on supplemented MS. When roots were plated on nonsupplemented MS, contaminating Alternaria spp. often suppressed Colletotrichum growth. Healthy plants did not yield C. acutatum growth from roots as opposed to the presence of contaminating Alternaria spp.

All isolates from different parts of diseased strawberry plants (roots, vegetative parts, and fruits) produced masses of salmon-orange acute conidia (average size $15 \times 4 \mu \mathrm{m}$ ) in dense white mycelium. This morphology is typical of $C$. acutatum grown on supplemented MS or PDA.

Quantification of $C$. acutatum in roots and the rhizosphere. The roots and rhizosphere of diseased plants growing in soil or perlite growth substrate, which were stunted, chlorotic and had a decayed and necrotic root system, were assessed for $C$. acutatum colonization by plating on supplemented MS. Root segments of all tested plants yielded colonies of $C$. acutatum. Percentage of root infections were $56 \pm 8$ and $60 \pm 12$ for field and perlite grown plants, respectively. However, the level of $C$. acutatum in the rhizosphere of plants in perlite growth substrate was approximately 2.5 times higher than that in field soil $(18,750 \pm 3,375$ and $7,600 \pm 2,150 \mathrm{CFU} / \mathrm{g}$, respectively).

Foliar and root pathogenicity assays. Four $C$. acutatum isolates from fruits and roots were used to inoculate the foliage and roots of strawberry plants to determine whether symptom development could be affected by the source of the isolate. The tested isolates, regardless of whether they originated from roots or fruits, caused typical anthracnose symptoms on petioles, leaves, and stolons of both cvs. Chandler and Sharon 7 to 10 days after inoculation. After 30 days, $100 \%$ mortality of all foliar-inoculated plants was observed, as compared to $0 \%$ for the water control plants, which remained healthy thereafter.

The effects of isolate origin and duration of root dipping on plant mortality were examined with cvs. Chandler and Sharon. A mortality rate of 90 to $100 \%$ was recorded in both cultivars after dipping roots for various periods $(10 \mathrm{~min}, 4 \mathrm{~h}$, or $18 \mathrm{~h}$ ) in conidial suspensions of isolates originating from roots and fruits (Table 2). Surviving plants exhibited symptoms of stunting and chlorosis. Root segments from the necrotic tissue of the killed plants, plated on supplemented MS, were $100 \%$ infected with C. acutatum. Extended, continuous dipping of roots for 4 and $18 \mathrm{~h}$ in water alone caused considerable plant mortality of 15 and $40 \%$ respectively, possibly due to anaerobic conditions, because no contamination by $C$. acutatum was observed after root plating (Table 2). Mortality of plants caused by each isolate at each dipping duration differed significantly $(P<0.001)$ from the water controls. The interaction of isolate and dipping duration was significant $(P=0.019)$, whereas no significant differences were observed in plant mortality for each isolate at each dipping duration $(P=0.05)$ (Table 2).

TABLE 2. Mortality (percent) of strawberry plants 21 days after dipping roots for various time periods in conidial suspensions of Colletotrichum acutatum isolates from roots and fruits

\begin{tabular}{lccc}
\hline & \multicolumn{3}{c}{ Dipping duration } \\
\cline { 2 - 4 } Isolate and origin & $10 \mathrm{~min}$ & $4 \mathrm{~h}$ & $18 \mathrm{~h}$ \\
\hline Control $\left(\mathrm{H}_{2} \mathrm{O}\right)$ & 0 & 15 & 40 \\
TUT-106A (fruit) & 90 & 95 & 100 \\
TUT-112A (fruit) & 95 & 95 & 100 \\
TUT-127A (root) & 90 & 95 & 100 \\
TUT-137A (root) & 95 & 100 & 100
\end{tabular}

\begin{tabular}{lrrr} 
& \multicolumn{3}{c}{ Analysis of variance } \\
\cline { 2 - 4 } Source & $\mathrm{MS}^{\mathrm{a}}$ & \multicolumn{1}{c}{$F$} & $P$ \\
\hline Isolate & 7,297 & 218.9 & 0.001 \\
Dipping duration & 493 & 14.9 & 0.001 \\
Isolate $\times$ dipping & 114 & 3.4 & 0.019 \\
duration & & & \\
\hline
\end{tabular}

${ }^{\text {a }}$ Mean square.
Vegetative compatibility grouping of isolates. A group of 10 isolates was chosen for the initial test of vegetative compatibility. Three isolates of this group (TUT-5954, TUT-232:1, and TUT232:2) were obtained from plant clinics, and seven were from stolons (TUT-8V, TUT-9A, TUT-73A, and TUT-75A) or crown tissue (TUT-6AB, TUT-7E, and TUT-22A) of diseased plants from two locations (Table 1). A total of 112 nit mutants were obtained from these isolates. Attempts to phenotype the mutants by growing them on media containing nitrate, nitrite, hypoxanthine, or ammonium as the nitrogen source $(2,5,21)$ were unsuccessful: their growth on both nitrite and hypoxanthine was leaky to profuse, and differences, if any, were uncertain.

The mutants of each isolate were first paired among themselves to determine complementation within isolates, and 16 representative mutants were then paired in all possible interisolate combinations. All mutants formed stable complementary heterokaryons with at least some of the other mutants, and the pattern of heterokaryon formation indicated that all 10 isolates belonged to a single VCG.

nit mutants were generated from an additional 105 isolates and paired with representative complementary mutants of the first group. Formation of complementary heterokaryons indicated that 103 of these isolates belonged to the VCG defined by the first group, whereas isolates TUT-111A and TUT-742D were heterokaryon self-incompatible (2). A total of 39 randomly chosen mutants were divided into seven complementation groups comprised of 1, 1, 3, 3, 4, 7, and 20 mutants. The largest group (Table 3: group A) probably consists of nitl mutants, whereas the others should include one group of nit3 and five groups of NitM mutants (22). Results of approximately 700 pairings between 16 mutants representing the seven complementation groups, and random nit mutants from the 113 vegetatively compatible isolates of this study, are summarized in Table 3. Complementary heterokaryons were obtained in half of the pairings with group A mutants and in all pairings with group $\mathrm{F}$ and $\mathrm{G}$ mutants, whereas 86 to $99 \%$ of the pairings with mutants of groups B through E resulted in complementation. Consequently, any pair of mutants from different complementation groups B through $\mathrm{G}$ (Table 3) could serve as useful and dependable representatives of the local population of $C$. $a c$ utatum from strawberry in vegetative compatibility tests.

Comparison of Colletotrichum isolates by ap-PCR. Israeli isolates were categorized according to site, plot, cultivar, and strawberry-tissue origins (Table 1). Genomic DNA of 121 Israeli isolates from crown, fruit, and stolons were amplified by ap-PCR using four oligonucleotide primers, $(\mathrm{CAG})_{5},(\mathrm{GACA})_{4}$, (TGTC) $)_{4}$, and $(\mathrm{GACAC})_{3}$. Amplicons for each primer were nearly identical for

TABLE 3. Formation of complementary heterokaryons between 16 nitrate nonutilizing (nit) mutants representing 7 complementation groups and random nit mutants from 113 vegetatively compatible isolates of Colletotrichum acutatum from strawberry

\begin{tabular}{llccc}
\hline \multirow{2}{*}{$\begin{array}{l}\text { Comp. } \\
\text { group }\end{array}$} & \multicolumn{1}{c}{$\begin{array}{c}\text { Isolate/ } \\
\text { mutant }\end{array}$} & $\begin{array}{c}\text { No. of } \\
\text { pairings }\end{array}$ & Complementary heterokaryons \\
\cline { 5 - 5 } A & TUT-8V/24 & 33 & 17 & $\%$ \\
& TUT-22A/4 & 40 & 20 & 52 \\
& TUT-75A/5 & 32 & 16 & 50 \\
B & TUT-9A/3 & 37 & 35 & 50 \\
& TUT-22A/3 & 37 & 32 & 95 \\
C & TUT-5954/25 & 65 & 62 & 86 \\
& TUT-232:1/3 & 34 & 31 & 95 \\
& TUT-75A/4 & 33 & 30 & 91 \\
D & TUT-5954/18 & 101 & 98 & 91 \\
& TUT-6AB/12 & 28 & 27 & 97 \\
& TUT-232:1/9 & 30 & 29 & 96 \\
E & TUT-8V/23 & 30 & 29 & 97 \\
& TUT-73A/11 & 34 & 32 & 97 \\
& TUT-232:2/55 & 83 & 82 & 99 \\
F & TUT-7E/2 & 28 & 28 & 100 \\
G & TUT-232:1/4 & 54 & 54 & 100 \\
\hline a Complem & Thtation groups (comp. oroups) are arbitrarily designated A through G.
\end{tabular}

a Complementation groups (comp. groups) are arbitrarily designated A through $\mathrm{G}$. 
all isolates (data not shown). Representative Israeli isolates were then compared by ap-PCR to American reference strawberry isolates of C. acutatum (CA-310-1 and CA-330-1), C. fragariae (CF63-1), and two isolates of $C$. gloeosporioides representing discrete genotypes (CG-315-1 representing genotype Cgl-1 and CG-272-1 of genotype Cgl-2) (Fig. 2). Amplicons of the representative Israeli isolates were identical to those of the two U.S. C. acutatum isolates with primer $(\mathrm{GACA})_{4}$, and distinctly different from the $C$. fragariae and two C. gloeosporioides isolates (Fig. 2A). Similar results were observed with primers (TGTC) ${ }_{4},(\mathrm{CAG})_{5}$, and (GAC$\mathrm{AC})_{3}$ (Fig. 2B, C, and D, respectively). Slight polymorphisms were distinguished among the $C$. acutatum isolates from Israel and the United States (Fig. 2C and D, respectively).

Ap-PCR was also performed with DNA from an additional 20 isolates from diseased roots and compared to $C$. acutatum reference isolate CA-330-1. Identical amplicons were obtained using primer (GACA $)_{4}$ (Fig. 3), with slight differences between U.S. and Israeli isolates using primers $(\mathrm{CAG})_{5},(\mathrm{TGTC})_{4}$, and $(\mathrm{GACAC})_{3}$ (data not shown).

\section{DISCUSSION}

The main aim of this research was to identify the species of Colletotrichum responsible for the first outbreak of anthracnose disease in Israel, and to determine whether the same or different species incited root necrosis in strawberry nurseries and produc-

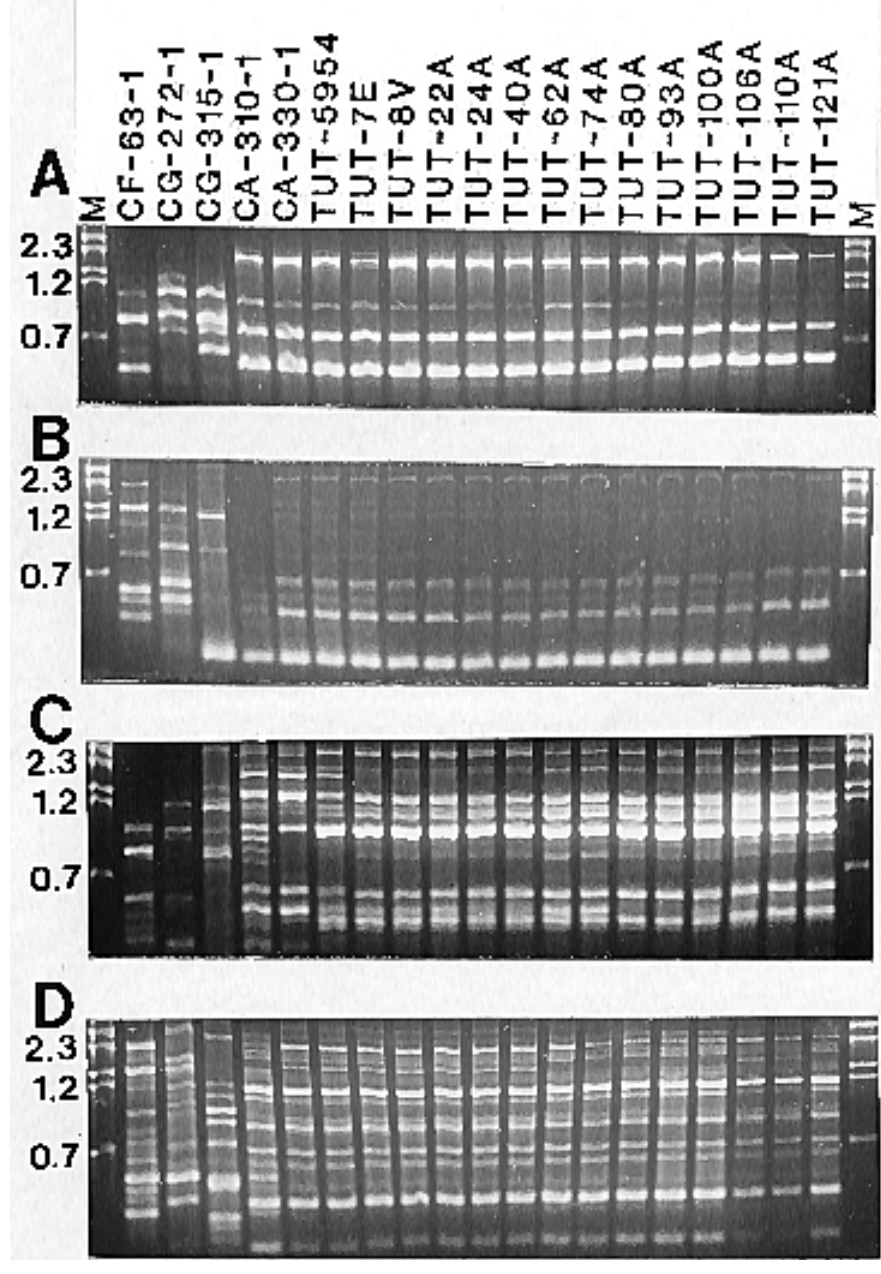

Fig. 2. Band patterns of arbitrarily primed, polymerase chain reaction-amplified genomic DNA from strawberry isolates of Colletotrichum fragariae (CF63-1), C. gloeosporioides (CG-272-1 and CG-315-1) and C. acutatum (U.S. references CA-310-1 and CA-330-1), and representative isolates from Israel (identified by prefix TUT-) using primers A, (GACA) $)_{4}, \mathbf{B},(\mathrm{TGTC})_{4}, \mathbf{C}$, $(\mathrm{CAG})_{5}$, and $\mathbf{D},(\mathrm{GACAC})_{3}$. Lane M: DNA markers (in kilobases). tion fields here. In a morphotaxonomic comparison, isolates from aboveground parts of anthracnose-affected plants and from necrotic, decayed roots of stunted chlorotic plants were uniform in appearance and classified as $C$. acutatum. Isolates from fruits and roots were equally pathogenic in artificial inoculations, suggesting that anthracnose and root necrosis were incited by the same pathogen. Isolates from all plant parts, including roots, were vegetatively compatible with one another, manifesting uniformity of the pathogen population. Likewise, the population was uniform in molecular DNA analyses, and its classification as $C$. acutatum was confirmed by comparisons with reference cultures of the major strawberry Colletotrichum pathogens.

Abundant anthracnose infestation was evident in many nurseries during the summers of 1995 and 1996. This resulted in massive collapse of transplants in soil-fumigated fields. Plants that die during the first 3 to 4 weeks after transplantation are routinely replaced by new transplants. Moreover, because plants are aligned with the drip-irrigation system, the replacement plants are planted in the same slots previously occupied by those that died, exposing them to the soilborne inoculum. Due to infestation in the nurseries, many farmers replanted infected but symptomless transplants in the same plots without refumigating the soil, thereby increasing inoculum density considerably. This was reflected in the high levels of $C$. acutatum populations in the rhizosphere of plants growing in naturally infested field soils. The unusual symptoms of root necrosis caused by $C$. acutatum may have resulted from root exposure to high inoculum density in the soil and to the repeated use of contaminated propagation material. Stunted plants with a decayed root system were not infected by systemic invasion of inoculum originating from the crown (Fig. 1). Root necrosis caused by $C$. acutatum has not been widely reported, although lesion development has been noticed on roots following artificial dip inoculations (7). Moreover, the pathogen was able to survive for up to 9 months in California soils (8) and to overwinter in fruit located above and below the soil surface in Ohio (37). Survival studies conducted in Israel have shown that populations of $\mathrm{C}$. $\mathrm{acu}$ tatum in artificially inoculated fruit buried for various periods in the soil decline rapidly (3 to 6 months) to untraceable incidence (S. Freeman, unpublished data). Therefore, the prospect of persistent soil contamination by a soilborne inoculum of $C$. acutatum seems unlikely, especially because soil fumigation is standard practice.

Although disease symptoms caused by the three major species, C. fragariae, C. acutatum, and C. gloeosporioides, are similar, it is of paramount importance to identify the causal agent of disease for regulatory and breeding purposes, as well as for the selection of control measures. For example, isolates of $C$. gloeosporioides are sensitive to benzimidazole fungicides as opposed to isolates of C. acutatum, which are not (1). Similarly, the slow-growing orange strains of $C$. acutatum are more tolerant to benomyl than the fastgrowing gray forms of $C$. gloeosporioides, both of which affect

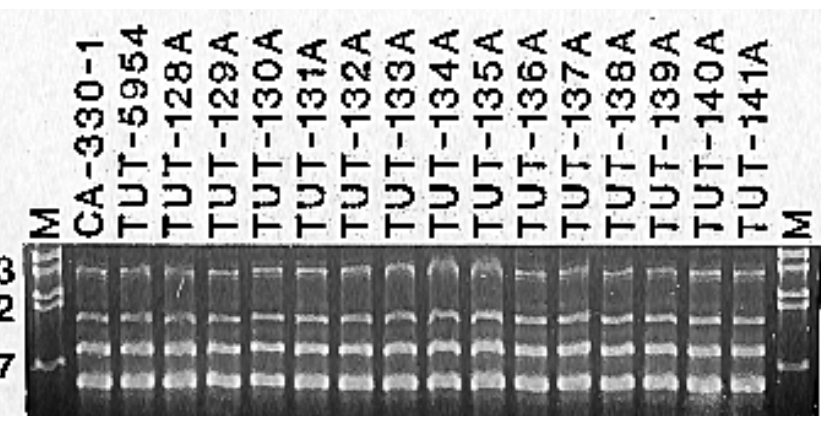

Fig. 3. Band patterns of arbitrarily primed, polymerase chain reaction-amplified genomic DNA of reference and representative Colletotrichum acutatum isolates from fruit (CA-330-1), crown (TUT-5954), and root (TUT-128A through TUT-141A) of strawberry using primer (GACA) $)_{4}$. Lane M: DNA markers (in kilobases). 
citrus $(3,24)$. Molecular tools have been successfully utilized to differentiate between the species of Colletotrichum responsible for strawberry anthracnose. Isolates of $C$. fragariae, $C$. acutatum, and C. gloeosporioides infecting strawberry were distinctly different in nuclear and A+T-rich DNA analyses, and ap-PCR $(13,14)$. Similarly, sequencing and restriction digest analyses of PCR-amplified rDNA have been used to differentiate between $C$. acutatum and other Colletotrichum species from strawberry $(12,30)$. In populations of $C$. acutatum and $C$. fragariae from strawberry, little genomic variation existed within each species using various molecular methods $(13,14)$. In contrast, high diversity was observed in populations of $C$. gloeosporioides from strawberry, which possess the perfect stage $(6,12,14,16)$. However, $C$. acutatum isolated from strawberries in Europe were discrete from American strawberry isolates (30). Likewise, isolates of $C$. acutatum from other hosts, e.g., peach and pecan, were discrete from the strawberry pathogen, which suggests that $C$. acutatum is not a uniform group (15). The uniformity of $C$. acutatum strawberry isolates in Israel, as illustrated by population grouping based on vegetative compatibility, suggests that the recent disease outbreak was due to a single introduction of the pathogen to Israel. The uniform ap-PCR profiles further indicate that these isolates belong to an asexually reproducing clonal population of apparent U.S. origin.

C. acutatum causing strawberry anthracnose is predominantly a pathogen of fruit, stolons and crowns. However, as demonstrated in this work, under the appropriate environmental, agrotechnical, and epidemiological conditions the pathogen can cause severe stunting and mortality of plants by infecting the root system.

\section{ACKNOWLEDGMENTS}

Contribution from the Agricultural Research Organization, The Volcani Center, Bet Dagan, Israel, 1967-E, 1996 Series. This research was supported in part by grant. 132-0967-96 from the chief scientist, Israel Ministry of Agriculture and Vegetable Growers Association awarded to S. Freeman. We thank F. Kleitman and Y. Nizani for their technical assistance.

\section{LITERATURE CITED}

1. Bernstein, B., Zehr, E. I., Dean, R. A., and Shabi, E. 1995. Characteristics of Colletotrichum from peach, apple, pecan, and other hosts. Plant Dis. 79:478-482.

2. Brooker, N. L., Leslie, J. F., and Dickman, M. B. 1991. Nitrate nonutilizing mutants of Colletotrichum and their use in studies of vegetative compatibility and genetic relatedness. Phytopathology 81:672-677.

3. Brown, A. E., Sreenivasaprasad, S., and Timmer, L. W. 1996. Molecular characterization of slow-growing orange and Key lime anthracnose strains of Colletotrichum from citrus as C. acutatum. Phytopathology 86:523-527.

4. Correll, J. C., Guerber, J. C., and Morelock, T. E. 1993. Vegetative compatibility and virulence of the spinach anthracnose pathogen, Colletotrichum dematium. Plant Dis. 77:688-691.

5. Correll, J. C., Klittich, C. J. R., and Leslie, J. F. 1987. Nitrate nonutilizing mutants of Fusarium oxysporum and their use in vegetative compatibility tests. Phytopathology 77:1640-1646.

6. Correll, J. C., Rhoads, D. D., and Guerber, J. C. 1993. Taxonomic, mtDNA haplotype, VCG, and morphological diversity of Colletotrichum spp. causing fruit-rot of apples. (Abstr.) Phytopathology 83:1412-1413.

7. Denoyes-Rothan, B., and Guerin, G. 1996. Comparison of six inoculation techniques with Colletotrichum acutatum on cold stored strawberry plants and screening for resistance to this fungus in French strawberry collections. Eur. J. Plant Pathol. 102:615-621.

8. Eastburn, D. M., and Gubler, W. D. 1990. Strawberry anthracnose: Detection and survival of Colletotrichum acutatum in soil. Plant Dis. 74: 161-163.

9. Elias, K. S., Zamir, D., Lichtman-Pleban, T., and Katan, T. 1993. Population structure of Fusarium oxysporum f. sp. lycopersici: Restriction fragment length polymorphisms provide genetic evidence that vegetative compatibility group is an indicator of evolutionary origin. Mol. Plant-Microbe Interact. 6:565-572.

10. Freeman, S. 1996. Occurrence and identification of Colletotrichum acu- tatum responsible for strawberry anthracnose in Israel. (Abstr.) Phytoparasitica 24:137.

11. Freeman, S. Occurrence of Colletotrichum acutatum responsible for strawberry anthracnose in Israel and molecular differentiation between the Colletotrichum complex. Acta Hort. In press.

12. Freeman, S., Katan, T., and Shabi, E. 1996. Characterization of Colletotrichum gloeosporioides isolates from avocado and almond fruits with molecular and pathogenicity test. Appl. Environ. Microbiol. 62:10141020.

13. Freeman, S., Pham, M., and Rodriguez, R. J. 1993. Molecular genotyping of Colletotrichum species based on arbitrarily primed PCR, A+Trich DNA, and nuclear DNA analyses. Exp. Mycol. 17:309-322.

14. Freeman, S., and Rodriguez, R. J. 1995. Differentiation of Colletotrichum species responsible for anthracnose of strawberry by arbitrarily primed PCR. Mycol. Res. 99:901-905.

15. Freeman, S., and Shabi, E. Cross-infection of subtropical and temperate fruits by Colletotrichum species from various hosts. Physiol. Mol. Plant Pathol. In press.

16. Gunnell, P. S., and Gubler, W. D. 1992. Taxonomy and morphology of Colletotrichum species pathogenic to strawberry. Mycologia 84:157-165.

17. Gupta, M., and Filner, P. 1991. Microsatellites amplify highly polymorphic DNA bands in SPAR of plant DNA. (Abstr. 1705). International Society for Plant Molecular Biology, Tucson, AZ.

18. Henz, G. P., Boiteux, L. S., and Lopes C. A. 1992. Outbreak of strawberry anthracnose caused by Colletotrichum acutatum in central Brazil. Plant Dis. 76:212.

19. Howard, C. M., Maas, J. L., Chandler, C. K., and Albregts, E. E. 1992. Anthracnose of strawberry caused by the Colletotrichum complex in Florida. Plant Dis. 76:976-981.

20. Katan, T., Gamliel, A., and Katan, J. 1996. Vegetative compatibility of Fusarium oxysporum from sweet basil in Israel. Plant Pathol. 45:656-661.

21. Katan, T., and Shabi, E. 1996. Vegetative compatibility among isolates of Colletotrichum gloeosporioides from almond in Israel. Eur. J. Plant Pathol. 102:597-600.

22. Katan, T., Zamir, D., Sarfatti, M., and Katan, J. 1991. Vegetative compatibility groups and subgroups in Fusarium oxysporum f. sp. radicislycopersici. Phytopathology 81:255-262.

23. Leslie, J. F. 1993. Fungal vegetative compatibility. Annu. Rev. Phytopathol. 31:127-150.

24. Liyanage, H. D., McMillan, R. T., Jr., and Kistler, H. C. 1992. Two genetically distinct populations of Colletotrichum gloeosporioides from citrus. Phytopathology 82:1371-1376.

25. Puhalla, J. E. 1985. Classification of strains of Fusarium oxysporum on the basis of vegetative compatibility. Can. J. Bot. 63:179-183.

26. Rodriguez, R. J., and Yoder, O. C. 1991. A family of conserved repetitive DNA elements from the fungal plant pathogen Glomerella cingulata (Colletotrichum lindemuthianum). Exp. Mycol. 15:232-242.

27. Sambrook, J., Fritsch, E. F., and Maniatis, T. 1989. Molecular Cloning: A Laboratory Manual. 2nd ed. Cold Spring Harbor Press, Cold Spring Harbor, NY.

28. Smith, B. J. 1986. First report of Colletotrichum acutatum on strawberry in the United States. Plant Dis. 70:1074.

29. Smith, B. J., and Black, L. L. 1990. Morphological, cultural, and pathogenic variation among Colletotrichum species isolated from strawberry. Plant Dis. 74:69-76.

30. Sreenivasaprasad, S., Brown, A. E., and Mills, P. R. 1992. DNA sequence variation and interrelationships among Colletotrichum species causing strawberry anthracnose. Physiol. Mol. Plant Pathol. 41:265-281.

31. Sturgess, O. W. 1954. A strawberry ripe fruit rot. Queensl. Agric. J. 78: 269-270

32. Sutton, B. C. 1992. The genus Glomerella and its anamorph Colletotrichum. Pages 1-26 in: Colletotrichum Biology, Pathology and Control. J. A. Bailey and M. J. Jeger, eds. CAB International, Wallingford, England.

33. Tu, J. C. 1985. An improved Mathur's medium for growth, sporulation and germination of spores of Colletotrichum lindemuthianum. Microbiosis 44:87-93.

34. von Arx, J. A. 1957. Die Arten der Gattung Colletotrichum Cda. Phytopathol. Z. 29:413-468.

35. Wasilwa, L. A., Correll, J. C., Morelock, T. E., and McNew, R. E. 1993. Re-examination of races of the cucurbit anthracnose pathogen Colletotrichum orbiculare. Phytopathology 83:1190-1198.

36. Weising, K., Weigand, F., Driesel, A. J., Kahl, A. J., Zischer, H., and Epplen, J. T. 1989. Polymorphic simple GATA/GACA repeats in plant genomes. (Abstr.) Nucleic. Acids Res. 17:10128.

37. Wilson, L. L., Madden, L. V., and Ellis, M. A. 1992. Overwinter survival of Colletotrichum acutatum in infected strawberry fruit in Ohio. Plant Dis. 76:948-950. 